\title{
Correlation Between Testosterone Replacement Treatment and Lower Urinary Tract Symptoms
}

\author{
Min Ho Lee ${ }^{1}$, Yu Seob Shin², Sung Chul Kam ${ }^{1,3,4}$ \\ ${ }^{1}$ Department of Urology, Gyeongsang National University Changwon Hospital, Changwon, Korea \\ ${ }^{2}$ Department of Urology, Jeonbuk National University Medical School, Jeonju, Korea \\ ${ }^{3}$ Department of Urology, College of Medicine, Gyeongsang National University, Jinju, Korea \\ ${ }^{4}$ Institute of Health Sciences, Gyeongsang National University, Jinju, Korea
}

Lower urinary tract symptoms (LUTS) are a cluster of voiding symptoms, such as weak stream, hesitancy, intermittency, urinary frequency, urgency, and nocturia. LUTS are frequent in elderly men and it considered the ultimate clinical symptoms of benign prostatic hyperplasia. With aging, male hypogonadism is increased which is defined as decreased ability of the testes to produce sperm and sex steroids because of a pituitary/hypothalamic, or testicular deficiency. In academic andrology associations, the term "male hypogonadism" is commonly used to categorize testosterone deficiency. Testosterone deficiency syndrome (TDS) is defined as a decrease in serum testosterone accompanied by symptoms such as libido decrease, depressive disorder, erectile dysfunction, and fatigue. Although the mechanism about testosterone-replacement therapy (TRT) effects on men with hypogonadism is not yet identified, TRT has been shown to effectively relieve the symptoms of TDS as well as LUTS by several studies. Although the present review demonstrates the effectiveness and safety of TRT in men with TDS by prior studies, future large scale of clinical trials should be conducted to present more high-quality evidence to clinicians and patients.

Keywords: Androgens; Benign prostatic hyperplasia; Hypogonadism; Lower urinary tract symptoms; Testosterone

- Conflict of Interest: No potential conflict of interest relevant to this article was reported.

\section{INTRODUCTION}

Lower urinary tract symptoms (LUTS) are a cluster of voiding symptoms, such as weak stream, hesitancy, intermittency, urinary frequency, urgency, and nocturia. LUTS are considered the ultimate clinical manifestation of benign prostatic hyperplasia (BPH) and benign prostatic enlargement, which cause bladder outlet obstruction [1,2]. With the increasing population of aging males, many recent studies have focused on extending life and prolonging good health in these individuals [1,3]. In this regard, many researchers have investigated testosterone, which is related to the differentiation and development of male genital organs.

Testosterone deficiency syndrome (TDS) is defined as a decrease in serum testosterone accompanied by symptoms such as libido decrease, depressive disorder, erectile dysfunction, and fatigue [4]. Several studies have reported that men experience a decline in testosterone levels beginning in their 40 s, and that about $30 \%$ of men meet the TDS criteria at the age of 70 years [5-7]. In the Boston Area Community Health Survey, the prevalence of symptomatic TDS among men aged 30-79 years was about $6 \%$ [8]. In addition, $26.5 \%$ of men in their 60 s and 70 s

Corresponding author: Sung Chul Kam (D) https://orcid.org/0000-0001-5403-3623 Department of Urology, Gyeongsang National University Changwon Hospital, 11 Samjeongja-ro, Seongsan-gu, Changwon 51472, Korea Email: kamsungchul@hanmail.net

Submitted: June 28, 2020 / Accepted after revision: July 21, 2020 
have reported bothersome LUTS [9].

Testosterone replacement therapy (TRT) has been shown to effectively relieve the symptoms of TDS [10-16]. However, the increasing use of TRT among men who are at risk for LUTS has raised concerns about its potential adverse effects [17]. In particular, TRT may exacerbate LUTS because androgens play an integral role in the development and growth of the prostate epithelium [18].

Longitudinal studies have not consistently associated testosterone with the development of LUTS after adjusting for age [19]. However, Favilla et al. reported that high levels of testosterone were associated with an increased risk of severe LUTS [18], which have been listed by the Endocrine Society as a relative contraindication to the TRT because the treatment may worsen symptoms [20]. Some studies have demonstrated that TRT does not aggravate LUTS among men with TDS, but their results have not yet been formally accepted [14,21-25]. Relatedly, several of the Endocrine Society's recommendations pertaining to TRT have recently been critically reevaluated [26].

Thus, in the present study, we performed a systematic review of the relationship between TRT and LUTS to clarify the available evidence.

\section{METHODS}

We searched relevant words in PubMed, Embase, and the Cochrane Library. The researched terms were as follows: "benign prostatic hyperplasia" AND "testosterone" AND "Hypogonadism" OR "International Prostate Symptom Score" OR "prostate volume" OR "safety" OR "adverse events". The present query was limited to retrospective or prospective human trials published in English. There were no limitations on publication date or follow-up period.

\section{TESTES, PROSTATE, AND ANDROGENS}

The testes are involved in spermatogenesis, which requires the seminiferous tubules to be intact and functioning. In addition, it has a steroidogenic function, secreting steroid sex hormones from the Leydig cells [27]. Spermatogenesis is a highly complex process involving subtle and continuous interactions between paracrine and autocrine regulators, of which testosterone is the most important [28]. The prostate weighs about 1-2 $\mathrm{g}$ at birth; in early puberty, it increases to approximately $10 \mathrm{~g}$ and finally to an average of $20 \mathrm{~g}$ in young adults [29-31]. After this phase, in which proliferation occurs in all 3 zones of the prostate gland (peripheral, central, and transitional zones [TZs]), approximately half of men show a second, selective growth phase in the TZ by their 50 s, while about $90 \%$ of men older than 80 years have undergone this second phase.

\section{Prostate Development and Androgen Levels}

During early fetal life, the prostate tissue differentiates via branching morphogenesis, which involves the organization of epithelial buds from the urogenital sinus into the surrounding mesenchymal tissue [32]. Studies using recombinant tissues composed of wild-type epithelium and androgen receptor (AR)-deficient mesenchyme have shown that the action of androgens on mesenchymal cells is necessary for prostate differentiation [33,34]. The ventral mesenchymal pad forms in a similar way in both male and female rats, but a normal prostate only develops when female rats are administered androgens [35], which also suggests that androgens play a role in early prostate development. The growth factor andromedin is androgen-dependent, but it is not clear whether AR action directly stimulates its secretion directly or rather whether androgens are indirectly involved in its activity or availability [32]. It is likely that AR only acts on epithelial cells at a later stage of differentiation, when it is necessary for the cells' exocrine secretory function and for their differentiation from basal to terminal luminal cells [36].

\section{Prostate Growth and Androgens}

Besides prostate development, androgens play an important role in prostate proliferation. Approximately $90 \%$ of prostatic androgens are in the form of dihydrotestosterone (DHT), which is mainly derived from the testis; only $10 \%$ comprise androgens of adrenal origin. The enzyme $5 a$-reductase converts testosterone to DHT, which is 5 times more potent than testosterone. In prostatic cells, DHT binds to the AR with high affinity [37-39].

In male fetuses, testosterone levels begin to increase in the 8th week of gestation and peak at the 16th week, when the concentration of testosterone is similar to that of adults. The hormone then declines to levels similar to those at birth.

Prostate growth occurs in 3 phases [32]. The first occurs during fetal life and ends at birth. After birth, testosterone increases again for 6 months - known as "mini-puberty" - and then decreases to undetectable levels during childhood $[32,40]$. With the decline in testosterone after mini-puberty, prostate volume decreases and its growth is negligible until puberty [41], when 
the second phase of growth occurs in response to the increase in testosterone. At this stage, cell development and differentiation occur, leading to the adult prostate. The third and last phase unfolds in middle-age and continues throughout adolescence. The prostate is unlike other organs in that it continues to grow throughout adulthood. However, the third phase corresponds to a decline in testosterone levels [42]. In this regard, while the development of the prostate during the first 2 phases is clearly androgen-dependent, the role of androgens in the third phase is still unclear [43].

\section{Testosterone Decline and BPH}

With aging, the incidence of $\mathrm{BPH}$ increases, and testosterone levels reduce because of impaired testicular function $[44,45]$. Specifically, testosterone decreases by about $2 \%$ annually in men [6]. The prevalence of TDS has ranged from $6 \%$ to $38 \%$ in several studies $[8,46]$. In previous studies, no significant relationship has been found between testosterone and prostate size [37-39], while in others, androgen replacement therapy was correlated with an improvement in LUTS [43,47]. These observations suggest that androgens are not directly related to the development of $\mathrm{BPH}$.

Conversely, several experimental and clinical studies have shown results that are inconsistent with this conclusion. For example, TRT causes BPH in young castrated dogs, and no one who underwent simple orchiectomy during childhood develops BPH [38]. Similarly, those with low levels of $5 a$-reductase type 2 show a relatively small prostate [48]. In Korean men with prostate cancer, androgen deprivation therapy (ADT) caused a decrease in prostate volume, improved urodynamic parameters, and alleviated LUTS [49]. Administration of 5a-reductase inhibitor decreases prostate size [50]. To explain these results, some authors have hypothesized that prostatic hyperplasia is related to intraprostatic concentrations of DHT rather than to circulating free testosterone levels [39].

However, in a small, randomized control trial there was no evidence of increased intraprostatic DHT in patients given TRT [23]. Favilla et al. reported no significant association between $\mathrm{BPH}$ and testosterone among 122 men with $\mathrm{BPH}$, even though LUTS is associated with testosterone levels [18].

\section{BPH/LUTS, Prostatic Inflammation, and Androgens}

The prostate is an organized, immunocompetent tissue that contains several immune cells, including lymphocytes, granulocytes, and macrophages. In this context, such cells are termed prostate-associated lymphoid tissue, which when activated can initiate a chronic immune response that persists even when primary inflammatory stimulants subsided. T helper I lymphocytes secrete interferon (IFN)- and interleukin (IL)-2, which are the main cytokines found in the early phase of BPH [51]. Lymphocytes and macrophages produce IFN-c and IL-17, which stimulate the production of chemokines by stromal cells. These interactions appear to induce prostate cell proliferation and BPH development $[52,53]$. The increase in IL-17 has been related to increased secretion by prostate stromal cells of IL- 6 and IL-8, which are important factors in prostate hyperplasia [54]. Many clinical studies have reported that patients with prostatitis are at greater risk for BPH/LUTS. Thus, inflammation may lead to BPH development of $[55,56]$. Despite these findings, it is unclear whether any preexisting conditions cause $\mathrm{BPH}$.

Relatedly, Vignozzi et al. evaluated prostate inflammation and tissue remodeling accompanied by decreased testosterone levels and high estrogen levels in male rabbits with metabolic syndrome (MetS). The authors suggested that hypogonadism plays a critical role in the development of prostate inflammation $[39,43]$. Together with other results, this indicates that, in patients with both hypogonadism and prostate inflammation, TRT may alleviate inflammatory changes and prevent the development of BPH or LUTS $[3,39,57,58]$. Fig. 1 shows these interactions schematically.

\section{BPH/LUTS and MetS}

MetS is a group of metabolic diseases that share insulin resistance as their main pathogenic mechanism. It is known as a risk factor for $\mathrm{BPH}$ development [3]. However, the mechanisms by which this occurs are highly complex; hyperinsulinism is associated with stimulation of the insulin-like growth factor (IGF)-1 receptor, higher IGF-1 levels, lower IGF-1 binding, and higher free calcium in smooth muscle and neural cells. In addition, it activates the sympathetic nervous system and increases the tone of prostatic smooth muscle [58]. Therefore, insulin-sensitizing drugs are recommended to treat MetS [59,60].

In a large British study, the risk of MetS was 37\% higher in men with $\mathrm{BPH}$ than in those without [32]. A review of 8 studies including a total of 5,403 men with MetS showed a significantly larger prostate and a TZ volume that was $4 \mathrm{~mL}$ greater [61]. One study involved 171 men with a mean age of $36.5 \pm 8.3$ years who had visited the urology clinic for counsel about infertility. The results showed that the severity of MetS was associated with a larger prostate volume [62]. In the Prostate Cancer Pre- 


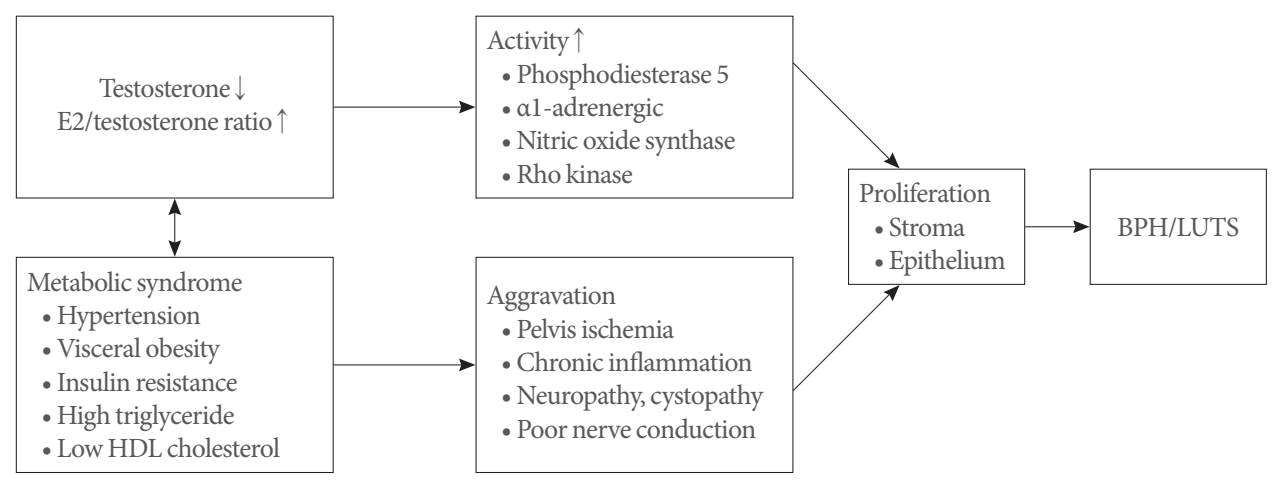

Fig. 1. Possible interactions between the testosterone deficiency and development of lower urinary tract symptoms. BPH, benign prostatic hyperplasia, E, estrogen, HDL, high-density lipoprotein, LUTS, lower urinary tract symptoms.

vention Trial, new occurrence of BPH over a 10-year follow-up was predicted by higher serum C-reactive protein and IL-6 levels at baseline [63], suggesting that conditions characterized by systemic inflammation, such as MetS, might be implicated in BPH development [58,64-66].

\section{MALE HYPOGONADISM}

Male hypogonadism is defined as decreased ability of the testes to produce sperm and sex steroids because of a pituitary/hypothalamic, or testicular deficiency $[27,67]$. The latter is known as primary hypogonadism, while the former is termed secondary or central hypogonadism. In academic andrology associations, the term "male hypogonadism" is commonly used to categorize testosterone deficiency, which is associated with infertility.

\section{Definition and Diagnosis of TDS}

When low testosterone is related to age and/or comorbidity (e.g., hypertension, coronary vascular disease, obesity, dyslipidemia, impaired insulin sensitivity) and is associated with symptoms (e.g., decreased libido, erectile dysfunction, fatigue, weakness) and signs (e.g., increased abdominal fat, reduced muscle and bone mass, gynecomastia, and small testes), it can be defined as TDS [11,67], which is a mixed type of hypogonadism involving both central and peripheral components [16].

Laboratory measurements should be performed in the morning or within 2 hours of getting up because testosterone levels show circadian variations [68]. In many laboratories, the lower normal limit is between 250 and $350 \mathrm{ng} / \mathrm{dL}(8.7-12.2 \mathrm{nmol} / \mathrm{L})$. However, if patients with borderline levels of testosterone, their free testosterone or sex hormone-binding globulin should be measured [67-69]. According to other guidelines, TRT is rec- ommended to subjects with levels $<8 \mathrm{nmol} / \mathrm{L}(231 \mathrm{ng} / \mathrm{dL})$, while those with level $>12 \mathrm{nmol} / \mathrm{L}$ ( $346 \mathrm{ng} / \mathrm{dL}$ ) do not require TRT. If the patient's testosterone level is between 8 and 12 $\mathrm{nmol} / \mathrm{L}$ and they show hypogonadal symptoms (mentioned above), TRT might be seriously considered $[67,69,70]$. Additionally, Wu et al. [71] newly defined TDS based on data from the EMAS study. They mentioned a syndromic association between low testosterone levels $(<11 \mathrm{nmol} / \mathrm{L})$ and sexual symptoms, namely decreased libido and erectile dysfunction [71].

\section{TRT ON TDS}

Patients with TDS should be evaluated individually to ensure that clinicians select the best-matched treatment. The types of TRT are presented in Table 1. No treatment guidelines are available for TDS, although if the low testosterone levels are related to any other comorbidities, it should be corrected at first [16]. However, TRT is the only treatment choice in cases of primary hypogonadism. According to the 2015 cardiovascular risk advisory, the Food and Drug Administration approved TRT specifically to treat men with low testosterone levels caused by disorders of the testes, brain, or pituitary gland that can cause hypogonadism, but not to treat men who only showed age-related low testosterone [25]. Finally, clinicians should consider whether the benefits of TRT overcome the potential risks. Currently, different types and methods of TRT are available.

\section{General Thinking About TRT and BPH/LUTS}

In the past, clinicians rose several concerns about the risk of BPH/LUTS and acute urinary retention after TRT, based on a report by Huggins and Hodges in the 1940s, who studied a small number of patients with metastatic prostate cancer and 
Table 1. Available types of testosterone replacement therapy

\begin{tabular}{lll}
\hline Type & \multicolumn{1}{c}{ Dosage } & \multicolumn{1}{c}{ Concerns } \\
\hline Intranasal & $11 \mathrm{mg}, 3$ times/day & Headache, upper respiratory symptoms \\
Buccal & $30 \mathrm{mg}, 2$ times/day & Taste alteration, oral mucosal irritation \\
Transdermal & & \\
Gel & & \\
$\quad$ Fortesta & $10-70 \mathrm{mg} /$ day & Risk of exposure to women or child \\
$\quad$ Androgel $1 \%$ & $50-100 \mathrm{mg} /$ day & \\
$\quad$ Testim 1\% & $50-100 \mathrm{mg} /$ day & \\
Solution & $30-120 \mathrm{mg} /$ day & Apply to axilla \\
Patch & $2-4 \mathrm{mg} /$ day & Frequent skin eruption \\
Inject/intramuscular & & \\
Testosterone enanthate & $50-400 \mathrm{mg} / \mathrm{every} 1-4$ weeks & T levels fluctuation \\
Testosterone undecanoate & $750 \mathrm{mg}$ for entry & Pulmonary embolism \\
& $750 \mathrm{mg} 4$ weeks later & Anaphylaxis \\
Pellets & $750 \mathrm{mg}$ then every 10 weeks & \\
\hline
\end{tabular}

found that castration resulted in disease regression and that only one patient who had undergone TRT showed cancer extension [72]. Holmäng et al. [73] reported that prostate volume may increase by approximately $12 \%$ with TRT. However, observational studies have failed to show that testosterone levels are significantly correlated with $\mathrm{BPH}$, and clinical trials have found no definite correlation with serum prostate-specific antigen (PSA) or prostate volume in patients with normal testosterone levels [74]. Previous major urological guidelines have reflected these concerns $[67,75]$. However, the current TRT guidelines of the European Association of Urology no longer regard severe LUTS (International Prostate Symptom Score [IPSS] >19) as an absolute contraindication, and regarded as a relative contraindication [76]. The guidelines also note that this paradox is not yet supported by strong clinical evidence, and that, if LUTS is treated appropriately, it is no longer a definite contraindication to TRT.

Furthermore, TRT may improve nocturia, which is the most bothersome LUTS in men with TDS. Testosterone levels may be correlated with circadian rhythms and sleep quality, which are perturbed by nocturia [77]. Indeed, several studies have reported that TDS has a negative effect on overall sleep quality, and that this can be attenuated by TRT [77].

Conversely, with regards to reducing testosterone levels in patients with LUTS, Washino et al. [78] reported that ADT significantly reduced prostate size in patients with prostate cancer, but increased nocturia in patients with mild LUTS. The authors reasoned that $\mathrm{ADT}$ suppresses serum levels of testosterone in older men, which may disrupt the urine concentrating function of the kidneys by decreasing circulating vasopressin and vasopressin binding sites, resulting in the development of nocturnal polyuria. Although controversies exist, TRT adaptation has rapidly increased, especially in males with TDS [79].

\section{Evidence for the Benefits of TRT in BPH/LUTS}

Prior to the present evidence, we reviewed previous studies, which are presented in Table 2. Recent studies have reported that TRT does not worsen LUTS, but rather improves it. Indeed, several studies have shown that testosterone plays a significant role in bladder and urinary sphincter function.

Similar to human clinical trials, animal studies have shown that TRT can improve LUTS. Tek et al. [80] reported that TRT improves LUTS and bladder function, showing increased bladder capacity and compliance, as well as decreased detrusor pressure at maximum flow rate (Qmax). In addition, Celayir [81] evaluated the relationship between bladder function and testosterone levels in castrated rabbits with or without TRT. Bladder capacity and compliance improved after 5 and 10 days in the TRT subjects, but decreased thereafter and returned to baseline levels after 30 days. This suggests that TRT is related to bladder capacity and compliance. In another rabbit study, ARs were found in the pelvic autonomic nervous system, detrusor 


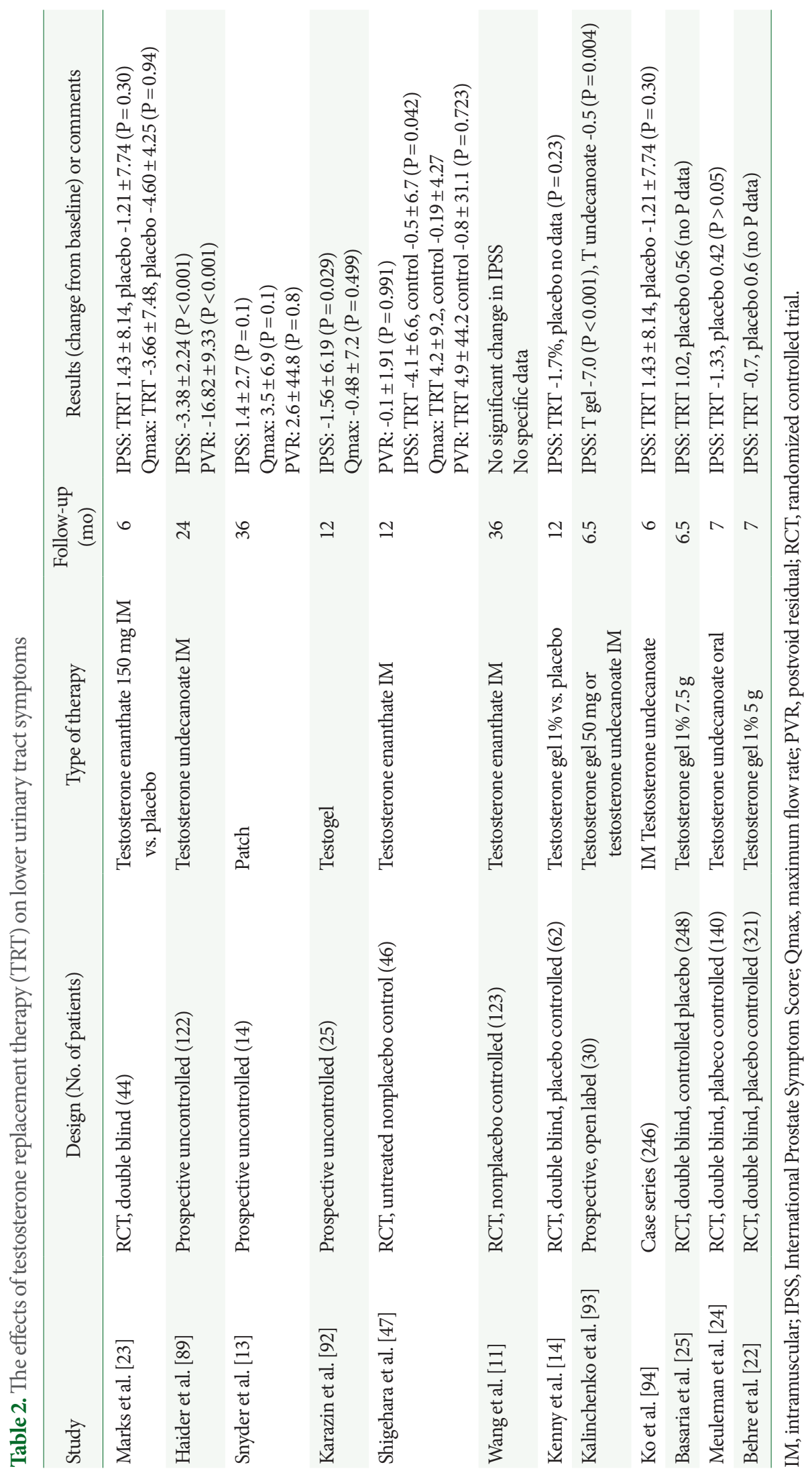


muscle, bladder mucosa, striated sphincter, and urethral mucosa. In the case of rats, abundant ARs were found in the pelvic autonomic nervous system [82].

Wilt et al. [83] investigated prostate cancer treatment outcomes and reported that urinary incontinence ( $\geq 1$ time/day) occurred in 35\% of men after radical prostatectomy and in $12 \%$ of men after radiotherapy. Surprisingly, among those who were only treated using ADT, 11\% complained of urinary incontinence, perhaps because of external aging-related degenerative changes in the urinary striated sphincter. Testosterone levels are associated with muscle quality and quantity [84], which might be why a decline in testosterone levels stimulates apoptosis [85]. As early as 1938, Walther and Willoughby [86] used TRT over 2 years in 15 men with BPH/LUTS, but their study was overlooked or neglected for some period. Pearl et al. [87] found no significant relationship between TRT and IPSS in 120 men in a 1-year follow-up study. Interestingly, in many men treated using TRT, IPSS scores were decreased by more than 3 points. Yassin et al. [88] performed a prospective observational study to evaluate the effects of TRT on LUTS in 261 men with TDS. The mean IPSS significantly improved from 10.35 to 6.58 during a median follow-up of 42.3 months. Shigehara et al. [47] performed a randomized trial for 1 year among 52 men with BPH/LUTS. They reported that post-TRT IPSS $(12.5 \pm 9.5)$ was significantly improved compared with baseline IPSS (15.7 \pm 8.7), and that Qmax was also improved, while postvoid residual (PVR) was not. Haider et al. [89] treated 117 men with TDS (mean age, $59.5 \pm 6.0$ years) using injectable testosterone undecanoate (1,000 mg) for 3 months. The results showed LUTS improvement. Both IPSS and PVR decreased, but no change was observed in total prostate volume. One multinational, multicenter study involved 999 men with both TDS and prostate cancer (mean age, $59.1 \pm 10.5$ years) who were followed up for a median of 3 years. A total of $75 \%$ had TRT, while $25 \%$ had no TRT. The TRT group showed LUTS improvement compared with the untreated group [90]. Kohn et al. [91] performed a systematic meta-analysis of 14 trials involving a total of 2,029 men to evaluate whether TRT indeed exacerbates LUTS. There were no significant differences in IPSS changes from baseline between the TRT and placebo treatment groups. The authors concluded that TRT does not worsen LUTS in men with TDS.

In addition, nocturia is prevalent among elderly men with LUTS and is one of the most serious symptoms. Shigehara et al. [77] reviewed the effects of TRT and nocturia. Testosterone activates endothelial nitric oxide synthase in the pelvis, increasing nitric oxide concentration in the blood vessel tissues. This may result in the dilatation of pelvic blood vessels and relief of pelvic ischemic change. Previous studies have reported that TRT for 1 year in men with TDS conferred increased maximal bladder capacity and bladder compliance, and that it decreased detrusor pressure at Qmax $[47,87,93,94]$. Therefore, there is enough evidence to treat men with TDS without unnecessary concerns about LUTS. However, there is still a lack of large, double-blind, randomized clinical trials, more clinical studies should be conducted to identify the exact beneficial effects of testosterone.

\section{Evidence for TRT Risk in BPH/LUTS}

Historically, clinicians have been concerned that TRT increases LUTS, but the present study found no evidence of significant exacerbation of LUTS after TRT, although many studies have excluded subjects with severe LUTS at baseline [91].

Pearl et al. [87] retrospectively studied 120 men with TDS who underwent TRT and reported that the treatment carries a low risk of exacerbating LUTS and that the changes in PSA levels were minor.

Several studies have stated that TRT in older men with TDS alters PSA levels, but that it rarely increases over the normal upper level. However, TDS constitutes a relative contraindication to TRT, according to several guidelines $[67,69,76]$.

\section{CONCLUSIONS}

The present review showed no evidence to support warnings that TRT worsens LUTS in men with TDS. TRT is already used worldwide as a treatment for TDS, and much evidence is still emerging regarding this treatment. Furthermore, TRT may also improve nocturia in men with TDS. Therefore, it is enough to warn patients that LUTS may worsen after TRT. However, further high-quality evidence is needed to inform clinicians using TRT to treat men with both TDS and severe LUTS.

\section{AUTHOR ORCID}

Yu Seob Shin

0000-0002-1126-3821

Sung Chul Kam

0000-0001-5403-3623

Min Ho Lee

0000-0001-8938-145X

\section{AUTHOR CONTRIBUTION STATEMENT}

- Conceptualization: SCK 
- Data curation: $M H L, Y S S, S C K$

- Formal analysis: $M H L$

- Methodology: $M H L$

- Project administration: SCK

- Visualization: $M H L$

-Writing-original draft: $M H L$

- Writing-review \& editing: YSS, SCK

\section{REFERENCES}

1. Park J, Kim ES, Lee YJ, Lee HS, Seo JT. Sex differences in lower urinary tract symptoms in older Korean adults living in rural areas: prevalence, quality of life, and associated factors. Int Neurourol J 2018;22:212-9.

2. Ko IG, Hwang L, Jin JJ, Kim SH, Han JH, Jeon JW, et al. Add-on therapy with the $\alpha$-blockers tamsulosin and naftopidil improves voiding function by enhancing neuronal activity in prostatic hyperplasia rats. Int Neurourol J 2018;22:20-9.

3. Traish AM, Johansen V. Impact of testosterone deficiency and testosterone therapy on lower urinary tract symptoms in men with metabolic syndrome. World J Mens Health 2018;36:199-222.

4. Schubert M, Jockenhovel F. Testosterone deficiency syndrome in the aging male (TDS): definition, diagnostic and clinical aspects. J Endocrinol Invest 2005;28:23-7.

5. Feldman HA, Longcope C, Derby CA, Johannes CB, Araujo AB, Coviello $\mathrm{AD}$, et al. Age trends in the level of serum testosterone and other hormones in middle-aged men: longitudinal results from the Massachusetts male aging study. J Clin Endocrinol Metab 2002;87:589-98.

6. Harman SM, Metter EJ, Tobin JD, Pearson J, Blackman MR. Longitudinal effects of aging on serum total and free testosterone levels in healthy men. Baltimore Longitudinal Study of Aging. J Clin Endocrinol Metab 2001;86:724-31.

7. DeLay KJ, Kohler TS. Testosterone and the prostate: artifacts and truth. Urol Clin N Am 2016;43:405-12.

8. Araujo AB, Esche GR, Kupelian V, O’Donnell AB, Travison TG, Williams RE, et al. Prevalence of symptomatic androgen deficiency in men. J Clin Endocrinol Metab 2007;92:4241-7.

9. Kupelian V, Wei JT, O’Leary MP, Kusek JW, Litman HJ, Link CL, et al. Prevalence of lower urinary tract symptoms and effect on quality of life in a racially and ethnically diverse random sample: the Boston Area Community Health (BACH) Survey. Arch Intern Med 2014;166:2381-7.

10. Wang C, Alexander G, Berman N, Salehian B, Davidson T, McDonald V, et al. Testosterone replacement therapy improves mood in hypogonadal men-a clinical research center study. J Clin Endocrinol Metab 1996;81:3578-83.

11. Wang C, Swerdloff RS, Iranmanesh A, Dobs A, Snyder PJ, Cunningham G, et al. Transdermal testosterone gel improves sexual function, mood, muscle strength, and body composition parameters in hypogonadal men. J Clin Endocrinol Metab 2000;85:283953.

12. Seidman SN, Rabkin JG. Testosterone replacement therapy for hypogonadal men with SSRI-refractory depression. J Affect Disord 1998;48:157-61.

13. Snyder PJ, Peachey H, Berlin JA, Hannoush P, Haddad G, Dlewati A, et al. Effects of testosterone re-placement in hypogonadal men. J Clin Endocrinol Metab 2000;85:2670-7.

14. Kenny AM, Kleppinger A, Annis K, Rathier M, Browner B, Judge JO, et al. Effects of transdermal testosterone on bone and muscle in older men with low bioavailable testosterone levels, low bone mass, and physical frailty. J Am Geriatr Soc 2010;56:1134-43.

15. Dobs AS, Meikle AW, Arver S, Sanders SW, Caramelli KE, Mazer NA. Pharmacokinetics, efficacy, and safety of a permeation-enhanced testosterone transdermal system in comparison with biweekly injections of testosterone enanthate for the treatment of hypogonadal men. J Clin Endocrinol Metab 1999;84:3469-78.

16. Corona G, Vignozzi L, Sforza A, Maggi M. Risks and benefits of late onset hypogonadism treatment: an expert opinion. World J Mens Health 2013;31:103-25.

17. Baillargeon J, Urban RJ, Ottenbacher KJ, Pierson KS, Goodwin JS. Trends in androgen prescribing in the United States, 2001 to 2011. JAMA Intern Med 2014;173:2013-4.

18. Favilla V, Cimino S, Castelli T, Madonia M, Barbagallo I, Morgia G. Relationship between lower urinary tract symptoms and serum levels of sex hormones in men with symptomatic benign prostatic hyperplasia. BJU Int 2010;106:1700-3.

19. Litman HJ, Bhasin S, O'Leary MP, Link CL, McKinlay JB. An investigation of the relationship between sex-steroid levels and urological symptoms: results from the Boston Area Community Health survey. BJU Int 2007;100:321-6.

20. Wang C, Nieschlag E, Swerdloff R, Behre HM, Hellstrom WJ, Gooren LJ, et al. Investigation, treatment, and monitoring of testosterone deficiency syndrome in males: ISA, ISSAM, EAU, EAA, and ASA recommendations. J Androl 2009;30:1-9.

21. Cui Y, Zhang Y. The effect of androgen-replacement therapy on prostate growth: a systematic review and meta-analysis. Eur Urol 2013;64:811-22.

22. Behre HM, Tammela TL, Arver S, Tolra JR, Bonifacio V, Lamche M, et al. A randomized, double-blind, placebo-controlled trial of tes- 
tosterone gel on body composition and health-related quality-oflife in men with hypogonadal to low-normal levels of serum testosterone and symptoms of androgen deficiency over 6 months with 12 months open-label follow-up. Aging Male 2012;15:198-207.

23. Marks LS, Mazer NA, Mostaghel E, Hess DL, Dorey FJ, Epstein JI, et al. Effect of testosterone replacement therapy on prostate tissue in men with testosterone deficiency syndrome: a randomized controlled trial. JAMA 2006;296:2351-61.

24. Meuleman EJ, Legros JJ, Bouloux PM, Johnson-Levonas AO, Kaspers MJ, Elbers JM, et al. Effects of long-term oral testosterone undecanoate therapy on urinary symptoms: data from a 1-year, placebo-controlled, dose-ranging trial in aging men with symptomatic hypogonadism. Aging Male 2015;18:157-63.

25. Basaria S, Harman SM, Travison TG, Hodis H, Tsitouras P, Budoff $\mathrm{M}$, et al. Effects of testosterone administration for 3 years on subclinical atherosclerosis progression in older men with low or lownormal testosterone levels: a randomized clinical trial. JAMA 2015;314:570-81.

26. Seftel AD, Kathrins M, Niederberger C. Critical update of the 2010 endocrine society clinical practice guidelines for male hypogonadism: a systematic analysis. Mayo Clin Proc 2015;90:1104-15.

27. Corona G, Rastrelli G, Forti G, Maggi M. Update in testosterone therapy for men. J Sex Med 2011;8:639-54.

28. Corona G, Rastrelli G, Vignozzi L, Maggi M. Emerging medication for the treatment of male hypogonadism. Expert Opin Emerg Drugs 2012;17:239-59.

29. Morgentaler A, Traish AM. Shifting the paradigm of testosterone and prostate cancer: the saturation model and the limits of androgen-dependent growth. Eur Urol 2009;55:310-20.

30. Rastrelli G, Corona G, Vignozzi L, Maseroli E, Silverii A, Monami $\mathrm{M}$, et al. Serum PSA as a predictor of testosterone deficiency. J Sex Med 2013;10:2518-28.

31. Schatzl G, Brössner C, Schmid S, Kugler W, Roehrich M, Treu T, et al. Endocrine status in elderly men with lower urinary tract symptoms: correlation of age, hormonal status, and lower urinary tract function. The Prostate Study Group of the Austrian Society of Urology. Urology 2000;55:397-402.

32. Schauer IG, Rowley DR. The functional role of reactive stroma in benign prostatic hyperplasia. Differentiation 2011;82:200-10.

33. Cunha GR, Chung LW. Stromal-epithelial interactions, I: induction of prostatic phenotype in urothelium of testicular feminized mice. J Steroid Biochem 1981;14:1317-24.

34. Vignera S, Condorelli RA, Russo GI, Morgia G, Calogero AE. Endocrine control of benign prostatic hyperplasia. Andrology 2016; 4:404-11.
35. Timms BG, Lee CW, Aumuller G, Seitz J. Instructive induction of prostate growth and differentiation by a defined urogenital sinus mesenchyme. Microsc Res Tech 1995;30:319-32.

36. Donjacour AA, Cunha GR. Assessment of prostatic protein secretion in tissue recombinants made of urogenital sinus mesenchyme and urothelium from normal or androgeninsensitive mice. Endocrinology 1993;132:2342-50.

37. Roehrborn CG. Pathology of benign prostatic hyperplasia. Int J Impot Res 2008;20(Suppl 3):S11-8.

38. Nicholson TM, Ricke WA. Androgens and estrogens in benign prostatic hyperplasia: past, present and future. Differentiation 2011; 82:184-99.

39. Vignozzi L, Rastrelli G, Corona G, Gacci M, Forti G, Maggi M. Benign prostatic hyperplasia: a new metabolic disease? J Endocrinol Invest 2014;37:313-22.

40. Kellokumpu-Lehtinen P, Santti R, Pelliniemi LJ. Correlation of early cytodifferentiation of the human fetal prostate and Leydig cells. Anat Rec 1980;196:263-73.

41. Cunha GR, Alarid ET, Turner T, Donjacour AA, Boutin EL, Foster BA. Normal and abnormal development of the male urogenital tract. Role of androgens, mesenchymal-epithelial interactions, and growth factors. Andrology 1992;13:465-75.

42. Wu FC, Tajar A, Pye SR, Silman AJ, Finn JD, O’Neill TW, et al. Hypothalamic-pituitarytesticular axis disruptions in older men are differentially linked to age and modifiable risk factors: the European Male Aging Study. Clin Endocrinol Metab 2008;93:2737-45.

43. Corona G, Baldi E, Maggi M. Androgen regulation of prostate cancer: where are we now? J Endocrinol Invest 2011;34:232-43.

44. Harman SM, Metter EJ, Tobin JD, Pearson J, Blackman MR. Baltimore Longitudinal Study of Aging. Longitudinal effects of aging on serum total and free testosterone levels in healthy men. Baltimore Longitudinal Study of Aging. J Clin Endocrinol Metab 2001;86: 724-31.

45. Lenzi A, Balercia G, Bellastella A, Colao A, Fabbri A, Foresta C, et al. Epidemiology, diagnosis, and treatment of male hypogonadotropic hypogonadism. J Endocrinol Invest 2009;32:934-8.

46. Mulligan T, Frick MF, Zuraw QC, Stemhagen A, McWhirter C. Prevalence of hypogonadism in males aged at least 45 years: the HIM study. Int J Clin Pract 2006;60:762-9.

47. Shigehara K, Sugimoto K, Konaka H, Iijima M, Fukushima M, Maeda Y, et al. Androgen replacement therapy contributes to improving lower urinary tract symptoms in patients with hypogonadism and benign prostate hypertrophy: a randomised controlled study. Aging Male 2011;14:53-8.

48. Imperato-McGinley J, Zhu YS. Androgens and male physiology 
the syndrome of 5alpha-reductase-2 deficiency. Mol Cell Endocrinol 2002;198:51-9.

49. Choi H, Chung H, Park JY, Lee JG, Bae JH. The influence of androgen deprivation therapy on prostate size and voiding symptoms in prostate cancer patients in korea. Int Neurourol J 2016;20:342-8.

50. Barkin J. Benign prostatic hyperplasia and lower urinary tract symptoms: evidence and approaches for best case management. Can J Urol 2011;18(Suppl):14-9.

51. Steiner GE, Stix U, Handisurya A, Willheim M, Haitel A, Reithmayr F, et al. Cytokine expression pattern in benign prostatic hyperplasia infiltrating $\mathrm{T}$ cells and impact of lymphocytic infiltration on cytokine mRNA profile in prostatic tissue. Lab Invest 2003; 83:1131-46.

52. Macoska JA. Chemokines and BPH/LUTS. Differentiation 2011; 82:253-60.

53. Lee JH, Kim Y, Park YW, Lee DG. Relationship between benign prostatic hyperplasia/lower urinary tract symptoms and total serum testosterone level in healthy middle-aged eugonadal men. J Sex Med 2014;11:1309-15.

54. Steiner GE, Newman ME, Paikl D, Stix U, Memaran-Dagda N, Lee $\mathrm{C}$, et al. Expression and function of pro-inflammatory interleukin IL-17 and IL-17 receptor in normal, benign hyperplastic, and malignant prostate. Prostate 2003;56:171-82.

55. Nickel JC. The overlapping lower urinary tract symptoms of benign prostatic hyperplasia and prostatitis. Curr Opin Urol 2006; 16:5-10.

56. Hung SC, Lai SW, Tsai PY, Chen PC, Wu HC, Lin WH, et al. Synergistic interaction of benign prostatic hyperplasia and prostatitis on prostate cancer risk. Br J Cancer 2013;108:1778-83.

57. Condorelli RA, Vicari E, Calogero AE, La Vignera S. Male accessory gland inflammation prevalence in type 2 diabetic patients with symptoms possibly reflecting autonomic neuropathy. Asian J Androl 2014;16:761-6.

58. Rastrelli G, Vignozzi L, Corona G, Maggi M. Testosterone and benign prostatic hyperplasia. Sex Med Rev 2019;7:259-71.

59. Mosli HH, Esmat A, Atawia RT, Shoieb SM, Mosli HA, AbdelNaim AB. Metformin attenuates testosterone-induced prostatic hyperplasia in rats: a pharmacological perspective. Sci Rep 2015;5: 15639.

60. Murff HJ, Roumie CL, Greevy RA, Grijalva CG, Hung AH, Liu X, et al. Thiazolidinedione and Metformin use and the risk of benign prostate hyperplasia in Veterans with diabetes mellitus. J Mens Health 2014;11:157-62.

61. Gacci M, Corona G, Vignozzi L, Salvi M, Serni S, De Nunzio C, et al. Metabolic syndrome and benign prostatic enlargement: a sys- tematic review and metaanalysis. BJU Int 2015;115:24-31.

62. Lotti F, Corona G, Vignozzi L, Rossi M, Maseroli E, Cipriani S, et al. Metabolic syndrome and prostate abnormalities in male subjects of infertile couples. Asian J Androl 2014;16:295.

63. Schenk JM, Kristal AR, Neuhauser ML, White E, Lin DW, Kratz M, et al. Biomarkers of systemic inflammation and risk of incident, symptomatic benign prostatic hyperplasia: results from the Prostate Cancer Prevention Trial. Am J Epidemiol 2010;171:571-82.

64. Gacci M, Sebastianelli A, Salvi M, Nunzio CD, Vignozzi L, Corona $\mathrm{G}$, et al. Benign prostatic enlargement can be influenced by metabolic profile: results of a multicenter prospective study. BMC Urol 2017;17:22.

65. Russo GI, Regis F, Spatafora P, Frizzi J, Urzi D, Cimino S, et al. Association between metabolic syndrome and intravesical prostatic protrusion in patients with benign prostatic enlargement and lower urinary tract symptoms (MIPS Study). BJU Int 2018;121:799-804.

66. Corona G, Gacci M, Maseroli E, Rastrelli G, Vignozzi L, Sforza A, et al. Clinical correlates of enlarged prostate size in subjects with sexual dysfunction. Asian J Androl 2014;16:767.

67. Buvat J, Maggi M, Guay A, Torres LO. Testosterone deficiency in men: systematic review and standard operating procedures for diagnosis and treatment. J Sex Med 2013;10:245-84.

68. Petering RC, Brooks NA. Testosterone therapy: review of clinical applications. Nor Am Fam Phy 2017;96:441-9.

69. Wang C, Nieschlag E, Swerdloff R, Behre HM, Hellstrom WJ, Gooren LJ, et al. Investigation, treatment and monitoring of testosterone deficiency syndrome in males: ISA, ISSAM, EAU, EAA and ASA recommendations. Eur J Endocrinol 2008;159:507-14.

70. Mohr BA, Guay AT, O’Donnell AB, McKinlay JB. Normal, bound and nonbound testosterone levels in normally ageing men: results from the Massachusetts Male Ageing Study. Clin Endocrinol 2005;62:64-73.

71. Wu FC, Tajar A, Beynon JM, Pye SR, Silman AJ, Finn JD, et al. Identification of testosterone deficiency syndrome in middle-aged and elderly men. N Engl J Med 2010;363:123-35.

72. Huggins C, Hodges CV. Studies on prostatic cancer. I. The effect of castration, of estrogen and androgen injection on serum phosphatases in metastatic carcinoma of the prostate. 1941. J Urol 2002; 168:9-12.

73. Holmäng S, Mårin P, Lindstedt G, Hedelin H. Effect of long-term oral testosterone undecanoate treatment on prostate volume and serum prostate-specific antigen concentration in eugonadal middle-aged men. Prostate 1993;23:99-106.

74. Morales A, Black AM, Emerson LE. Testosterone administration to men with testosterone deficiency syndrome after external beam ra- 
diotherapy for localized prostate cancer: preliminary observations. BJU Int 2009;103:62-4.

75. Bhasin S, Cunningham GR, Hayes FJ, Matsumoto AM, Snyder PJ, Swerdloff RS, et al. Testosterone therapy in men with androgen deficiency syndromes: an endocrine society clinical practice guideline. J Clin Endocrinol Metab 2010;95:2536-59.

76. Salonia A, Bettocchi C, Carvalho J, Corona G, Jones TH, Kadioglu A, et al. EAU Guidelines on Sexual and Reproductive Health. EAU guidelines 2020 [Internet]. Anheim (NL): European Association of Urology; c2020 [cited 2020 Jan 1]. Available from: https://uroweb. org/guideline/sexual-and-reproductive-health/.

77. Shigehara K, Izumi K, Mizokami A, Namiki M. Testosterone deficiency and nocturia: a review. World J Mens Health 2017;35:14-21.

78. Washino S, Hirai M, Saito K, Kobayashi Y, Arai Y, Miyagawa T. Impact of androgen deprivation therapy on volume reduction and lower urinary tract symptoms in patients with prostate cancer. Low Urin Tract Symptoms 2018;10:57-63

79. Liverman CT, Blazer DG, editors. Testosterone and aging: clinical research directions. Washington DC: The National Academies Press; 2004.

80. Tek M, Balli E, Cimen B, Efesoy O, Oğuz I, Cayan S. The effect of testosterone replacement therapy for bladder functions and histology in orchiectomized mature male rats. Urology 2010;75:886-90.

81. Celayir S. Effects of different sex hormones on male rabbit urodynamics: an experimental study. Horm Res 2003;60:215-20.

82. Yassin AA, El-Sakka AI, Saad F, Gooren LJ. Lower urinary-tract symptoms and testosterone in elderly men. World J Urol 2008;26: 359-64.

83. Wilt TJ, MacDonald R, Rutks I, Shamliyan TA, Taylor BC, Kane RL. Systematic review: comparative effectiveness and harms of treatments for clinically localized prostate cancer. Ann Intern Med 2008; 148:435-48.

84. Bhasin S, Tenover JS. Age-associated sarcopenia-issues in the use of testosterone as an anabolic agent in older men. J Clin Endocrinol Metab 1997;82:1659-60.

85. Badawi JK, Bosch R, Djurhuus JC, Hanna-Mitchel AT. Is testoster- one important in LUT function in men and women? Neurourol Urodyn 2017;36:859-62.

86. Walther HW, Willoughby RM. Hormonal treatment of benign prostatic hyperplasia. J Urol 1938;40:135-44.

87. Pearl JA, Berhanu D, François N, Masson P, Zargaroff S, Cashy J, et al. Testosterone supplementation does not worsen lower urinary tract symptoms. J Urol 2013;190:1828-33.

88. Yassin DJ, El Douaihy Y, Yassin AA, Kashanian J, Shabsigh R, Hammerer PG. Lower urinary tract symptoms improve with testosterone replacement therapy in men with late-onset hypogonadism: 5-year prospective, observational, longitudinal registry study. World J Urol 2014;32:1049-54.

89. Haider A, Gooren LJ, Padungtod P, Saad F. Concurrent improvement of the metabolic syndrome and lower urinary tract symptoms upon normalization of plasma testosterone levels in hypogonadal elderly men. Andrologia 2009;41:7-13.

90. Debruyne FMJ, Behre HM, Roehrborn CG, Maggi M, Wu FC, Schroder FH, et al. Testosterone treatment is not associated with increased risk of prostate cancer or worsening of lower urinary tract symptoms: prostate health outcomes in the Registry of Hypogonadism in Men. BJU Int 2017;119:216-24.

91. Kohn TP, Mata DA, Ramasamy R, Lipshultz LI. Effects of testosterone replacement therapy for lower urinary tract symptoms: a systematic review and meta-analysis. Eur Urol 2016;69:1083-90.

92. Karazindiyanoğlu S, Cayan S. The effect of testosterone therapy on lower urinary tract symptoms/bladder and sexual functions in men with symptomatic testosterone deficiency syndrome. Aging Male 2008;11:146-9.

93. Kalinchenko S, Vishnevskiy EL, Koval AN, Mskhalaya GJ, Saad F. Beneficial effects of testosterone administration on symptoms of the lower urinary tract in men with late-onset hypogonadism: a pilot study. Aging Male 2008;11:57-61.

94. Ko YH, Moon du G, Moon KH. Testosterone replacement alone for testosterone deficiency syndrome improves moderate lower urinary tract symptoms: one year follow-up. World J Mens Health 2013;31:47-52. 